\title{
Introduction to the Special Issues in Honor of Salvador Barberà's 65th birthday
}

\author{
Matthew O. Jackson • Hugo F. Sonnenschein
}

Published online: 17 November 2011

(C) The Author(s) 2011. This article is published with open access at SpringerLink.com

The size and quality of this two-volume special issue in honor of Salvador Barberà speaks to the wide scope of his contributions as a friend, co-author, mentor, and builder.

We begin by framing some of Salvador's important research contributions.

The theory of social choice is at the very center of economic analysis. In the late 1960s, following various contributions by William Vickrey, Robin Farquharson, Edward Clarke, Ted Groves, Alan Gibbard and Mark Satterthwaite, the notion of strategy-proofness took form and, together with ideas emerging in game theory, produced an "economics of incentives". This line of research became among the most fruitful work in all of social science of the last quarter of the twentieth century. Salvador Barberà is among the most influential scholars in this line of research, particularly on the voting models side. He stands among the world leaders.

In particular, Salvador Barberà's work on strategy-proofness has been of fundamental importance and he has made several seminal contributions. These begin with papers that follow from his Ph.D. thesis and are particularly concerned with strategyproofness when one allows some randomization in outcomes. Those papers helped uncover the role of chance or randomization in social decisions, and showed the limited extent to which that can help in mitigating individual incentives for manipulation. That work has recently sparked a series of interesting follow-up papers. Salvador's other important works on strategy-proofness in such rich domains include insightful proofs based on pivotal voter arguments and extensions to infinite settings (in work with Bezalel Peleg).

\footnotetext{
M. O. Jackson $(\bowtie)$

Department of Economics, Stanford University, Stanford, USA

e-mail: jacksonm@stanford.edu

H. F. Sonnenschein $(\varangle)$

Department of Economics, University of Chicago, Chicago, USA

e-mail: h-sonnenschein@uchicago.edu
} 
Many of Salvador's most important contributions on strategy-proofness come from analyzing a series of settings with restricted domains of preferences in which non-trivial and interesting methods of choosing allocations are possible. One example along these lines is the characterization of the voting rules that are non-manipulable when some set of voters is electing a group of people to join a club or society. There, Salvador, and his co-authors Hugo Sonnenschein and Lin Zhou, showed that certain quota-based voting methods, where a candidate is elected if a given number of votes are cast in the candidates favor, are the only anonymous voting systems that are strongly immune to individual manipulations. These systems, and some natural generalizations of them, are quite robust voting rules that appear in many practical settings, and this research provides general insights into settings that admit nontrivial strategy-proof rules.

Salvador's further investigations of nontrivial strategy-proof voting and allocations appear in a series of papers with various co-authors including Faruk Gul, Ennio Stacchetti, Matthew Jackson, Jordi Masso, Alejandro Neme, and Shige Serizawa. Several of those papers advance our understanding of the conditions under which a group of voters can make decisions on several different dimensions or issues simultaneously without being manipulable by self-interested individuals. Salvador has also provided some definitive answers to some of the questions concerning the design of strategyproof markets and systems of exchange in a paper with Matthew Jackson. He continues to derive new insights on the subject, and, for example, his recent work with Dolors Berga and Bernado Moreno has led to a much deeper and fundamental characterization of the preference domains that admit non-dictatorial and strategy-proof social choice functions.

His work is widely known and cited and has been profoundly influential in framing much research on the design of voting systems and institutions more generally, and strategy-proofness in particular. It would be difficult for anyone working on this subject not to cite at least one of Salvador's articles. He is currently writing a book on strategy-proofness, which should become the classic reference on this important subject.

His curiosity has also led Salvador to make important contributions on a wide array of questions in economic theory ranging from rationalizing individual decisions (in work with Birgit Grodal and with Prasanta Pattanaik), to how societies choose their constitutions (in work with Matthew Jackson), locate public facilities (in work with Carmen Bevia), and elect members who themselves become future voters (in work with Michael Maschler, Jonathan Shalev, and Andres Perea) or select from slates of candidates (in work with Danilo Coelho), as well as how societies should evaluate profiles of utility (in work with Bhaskar Dutta and Matthew Jackson). These works share a common thread of a careful theoretical analysis of individual and collective decision making, but are wide-ranging in their applications and insights.

These are a few highlights of a very distinguished research career, and Salvador continues to produce research of the highest quality. His substantial contributions in this regard have earned Salvador a number of high honors including his recent Pascual Madoz Prize, one of Spain's highest honors for a social scientist, as well as his Rey Juan Carlos Prize, the highest recognition for a Spanish economist, and his election as a Fellow of the Econometric Society.

Any description of Salvador's contributions to the profession would be very incomplete without noting that Salvador has also devoted much of his energies to building 
research communities and institutions within Spain, and bridges from them to the broader international research community. His list of accomplishments in this regard is most impressive. Let us list just a few prominent examples.

Salvador was among an important wave of Spanish economic researchers who in the late 1970s faced institutions that were arcane and whose funding was by international standards nonexistent. They had a mission to build modern economics in Spain and they have succeeded beyond what anyone might have imagined. Spain, and in particular Barcelona, is now one of the very strongest centers for economics in continental Europe. Salvador's efforts began with his return to Spain after finishing his $\mathrm{PhD}$, where he first spent 2 years in Madrid and then almost a decade in Bilbao. During that time, Salvador was one of the founders of ASSET, which helped foster serious and regular interaction among economic researchers in southern Europe. His efforts at building research communities continued to gather steam as he moved to the Autonoma in the late 1980s. There, Salvador played a central role in transforming the economics department into a world-class and vibrant research department. The foundation for economic research at the Autonoma had been already set in place with the creation of the IAE, and was energized by the return of Salvador. Salvador's efforts were pivotal in hiring many of the excellent researchers that form its backbone today, as well as raising its visibility internationally. In particular, Salvador successfully bid for and hosted the 1990 World Congress of the Econometric Society. This is perhaps the premiere meeting of economists, and is only held once every 5 years and attracts thousands of economists. It is easy to underestimate how much time and energy running such an enterprise took. The meeting was well-received and helped consolidate the Spanish community's standing in the international research arena. Salvador's trajectory has included many other such endeavors. He helped found the research center "CODE" in 1995. CODE is a research center that provides critical funding and stability to researchers in the economics department at the UAB (Universitat Autonoma de Barcelona). After CODE was on solid footing, in 2000, Salvador began serving as the first director of "ICREA," a very influential research organization that funds researchers in Catalonia. ICREA has been instrumental in encouraging researchers to return from abroad in all sorts of disciplines. In the last 5 years, Salvador has been a key partner in forging the Barcelona Graduate School of Economics, which helps the various economics programs in the Barcelona region become more than the sum of their parts, both in terms of educational mission and the interaction between the researchers. Salvador's latest brainchild, "MOVE," is now taking shape and is an institution that is helping to attract and retain key researchers in Barcelona, as well as sponsoring a wide range of meetings on critical topics, and bringing through world-class researchers as visitors. Of course, this list of Salvador's many important contributions in building research institutions and communities would not be complete without including Salvador serving as the General Secretary of Research and Technological Policies in the Spanish Ministry of Education and Science from 2004 to 2006! This clearly demonstrated Salvador's dedication to fostering and advancing research throughout Spain. In recent years, Salvador Barberà's reach in the support of science has broadened.

While the list above provides insight into Salvador's substantial role in fostering research and improving life within Spain, he has also been an active leader of the international research community. As a glimpse of this, Salvador has held the presidencies 
of the Society for Social Choice and Welfare and the Southern European Economic Association, and has served on a spectrum of editorial boards, from Social Choice and Welfare to Games and Economic Behavior, and has also served as a council member of the Econometric Society and of several of its key committees, as well as being a founding member of both the Society for Social Choice and Welfare and the Game Theory Society.

In celebration of Salvador's many contributions, we are very happy to present him with this special issue on behalf of his many grateful friends and colleagues.

The many papers in this special issue cluster around various themes that have been central to Salvador's research.

First and foremost, there are a number of papers relating to strategy-proofness, including those by Fuad Aleskerov, Daniel Karabekyan, M. Remzi Sanver and Vyacheslav Yakuba; Lars Elhers; Carmen Herrero and Ricardo Martínez; Michel Le Breton; Hans Peters, Souvik Roy and Ton Storcken; Regis Renault and Alain Trannoy; Arunava Sen; and John Weymark.

There are also a number of papers on social choice and political economy more generally, including those by Pablo Amorós, Ricardo Martínez, Bernardo Moreno and M. Socorro Puy; Alaitz Artabe, Annick Laruelle and Federico Valenciano; Gustavo Bergantiños, Jordi Massó and Alejandro Neme; Antonio Cabrales and Roberto Serrano; Josep M. Colomer and Humberto Llavador; Gabrielle Demange; M. C. Gallastegui, M. González-Eguino and I. Galarraga; Antonio Nicolo, Andrés Perea y Monsuwe and Paolo Roberti; Bezalel Peleg, Peter Sudhölter and José M. Zarzuelo; Clara Ponsati and Santiago Sanchez-Pages; John E. Roemer; and Joaquim Silvestre.

Finally, Salvador's works on decision making are well represented by contributions from Jorge Alcalde-Unzu, Miguel A. Ballester and Jorge Nieto; José C. R. Alcantud and Ritxar Arlegi; Walter Bossert and Kotaro Suzumura; Jacques Dreze; and Juan Urrutia Elejalde; and his dedication to research and science is nicely represented by a contribution by Javier Ruiz-Castillo.

In closing, we would like to thank the anonymous referees who responded to this in record time and helped make these issues a success. Also, we are extremely grateful to Victor Aguirregabiria and M. Angeles de Frutos who did heroic editorial work behind the scenes to make this all run smoothly and to keep our burden light.

\section{Selected works of Salvador Barberà in reverse chronological order}

Preference for Flexibility and the Opportunities of Choice (joint with B. Grodal), J Math Econ, forthcoming.

Individual versus group strategy-proofness: when do they coincide? (joint with D. Berga and B. Moreno), J Econ Theory 145(5), 1648-1674, 2010.

On the Rule of k Names (joint with D. Coelho), Games Econ Behav 70(1), 44-61, 2010. 
On the Weights of Nations: Assigning Voting Weights in a Heterogeneous Union (joint with M. O. Jackson), J Political Econ 114(2), 317-339, 2006.

Locating Public Facilities by Majority: Stability, Consistency and Group Formation (joint with C. Beviá), Games Econ Behavior 56(1), 185-200, 2006.

Voting by Committees under Constraints (joint with J. Massó and A. Neme), J Econ Theory 122, 185-205, 2005.

Choosing How to Choose: Self-Stable Majority Rules and Constitutions (joint with M. O. Jackson), Quart J Econ 119(3), 1011-1048, 2004.

On Coalition Formation: Durable Coalition Structures (joint with A. Gerber), Math Soc Sci 45, 185-203, 2003.

Supporting Others and the Evolution of Influence (joint with A. Perea), J Econ Dyn Control 26(12), 2051-2092, 2002.

Self-selection Consistent Functions (joint with C. Beviá), J Econ Theory 105(2), 263-277, 2002.

Strategy-proof Social Choice Correspondences (joint with B. Dutta and A. Sen), J Econ Theory 101, 374-394, 2001.

Voting for Voters: A Model of Electoral Evolution (joint with M. Maschler and J. Shalev), Games Econ Behav 37(1), 40-78, 2001.

Maximal Domains of Preferences Preserving Strategy-Proofness for Generalized Median Voters Schemes (joint with J. Massó and A. Neme), Soc Choice Welf 16(2), 321-336, 1999.

Strategy-Proof Voting on Compact Ranges (joint with J. Massó and S. Serizawa), Games Econ Behav 25(2), 272-291, 1998.

Strategy-Proof Probabilistic Rules for Expected Utility Maximizers (joint with A. Bogomolnaia and H. van der Stel), Math Soc Sci 35(2), 89-103, 1998.

Voting under Constraints (joint with J. Massó and A. Neme), J Econ mic Theory 76(2), 298-321, 1997.

Strategy-proof Allotment Rules (joint with M. O. Jackson and A. Neme), Games Econ Behav 18(1), 1-21, 1997.

Strategy-proof Exchange (joint with M. O. Jackson), Econometrica 63(1), 51-87, 1995. 
A Characterization of Strategy-proof Social Choice Functions for Economies with Pure Public Goods (joint with M. O. Jackson), Soc Choice Welf 11(3), 241-252, 1994.

Generalized Median Voter Schemes and Committees (joint with F. Gul and E. Stacchetti), J Econ Theory 61(2), 262-289, 1993.

Voting by Committees (joint with H. Sonnenschein and L. Zhou), Econometrica 59(3), 595-609, 1991.

Strategy-proof Voting Schemes with Continuous Preferences (joint with B. Peleg), Soc Choice Welf 7(1), 31-38, 1990.

Maximin, Leximin and the Protective Criterion:characterizations and comparisons (joint with M. O. Jackson), J Econ Theory 46(1), 34-44, 1988.

Falmagne and the Rationalizability of Stochastic Choices in Terms of Random Orderings (joint with P. K. Pattanaik), Econometrica 54(3), 707-715, 1986.

Collective Probabilistic Judgements (joint with F. Valenciano), Econometrica 51(4), 1033-1046, 1983.

Strategy-Proofness and Pivotal Voters: A Direct Proof of the Gibbard-Satterthwaite Theorem. Int Econ Rev 24(2), 413-417, 1983.

Implementability via Protective Equilibria (joint with B. Dutta), J Math Econ 10(1), 49-65, 1982.

Pivotal Voters: A New Proof of Arrow's Theorem. Econ Lett 6(1), 13-16, 1980.

Stable Voting Schemes, J Econ Theory 23(2), 267-274, 1980.

A Note on Group Strategy-Proof Decision Schemes, Econometrica 47(3), 637-640, 1979.

Majority and Positional Voting in a Probabilistic Framework. Rev Econ Stud 46(2), 379-389, 1979.

Preference Aggregation with Randomized Social Orderings (joint with H. Sonnenschein), J Econ Theory 18(2), 244-254, 1978.

The Manipulation of Social Choice Mechanisms that do not leave too much to chance, Econometrica 45(7), 1573-1588, 1977.

Manipulation of Social Decision Functions, J Econ Theory 15(2), 266-278, 1977. 


\section{Papers in the volume}

On Strategy-Proofness (alphabetically, by last name of first author)

- An individual manipulability of positional voting rules, by Fuad Aleskerov, Daniel Karabekyan, M. Remzi Sanver and Vyacheslav Yakuba.

- A characterization of the uniform rule without Pareto-optimality, by Lars Ehlers.

- Allocation problems with indivisibilities when preferences are single-peaked, by Carmen Herrero and Ricardo Martínez.

- Euclidean Preferences, Option Sets and Strategy-proofness, by Michel LeBreton.

- Strategy-proof voting rules on a multidimensional policy space for a continuum of voters with elliptic preferences, by Hans Peters, Souvik Roy and Ton Storcken.

- Assessing the Extent of Strategic Manipulation: the Average Vote Example, by Regis Renault and Alain Trannoy.

- The Gibbard random dictatorship theorem: a generalization and a new proof, byArunava Sen.

- A unified approach to strategy-proofness for single-peaked preferences, by John A. Weymark.

On Social Choice and Political Economy (alphabetically, by last name of first author)

- Deciding whether a law is constitutional, interpretable, or unconstitutional, Pablo Amorós, Ricardo Martínez, Bernardo Moreno and M. Socorro Puy.

- Preferences, actions and voting rules, by Alaitz Artabe, Annick Laruelle and Federico Valenciano.

- The division problem with maximal capacity constraints, by Gustavo Bergantiños, Jordi Massó and Alejandro Neme.

- Stochastically stable implementation, by Antonio Cabrales and Roberto Serrano.

- An agenda-setting model of electoral competition, by Josep M. Colomer and Humberto Llavador.

- Majority relation and median representative ordering, by Gabrielle Demange. 
- Cost effectiveness of a combination of instruments for global warming: a quantitative approach for Spain, by M. C. Gallastegui, M. González-Eguino and I. Galarraga.

- Equal Opportunity Equivalence in Land Division, by Antonio Nicolo, Andrés Perea y Monsuwe and Paolo Roberti.

- On the impact of independence of irrelevant alternatives: the case of two-person NTU games, by Bezalel Peleg, Peter Sudhölter and José M. Zarzuelo

- Optimism and commitment: An elementary theory of bargaining and war, by Clara Ponsati and Santiago Sanchez-Pages.

- The political economy of income taxation under asymmetric information: the twotype case, by John E. Roemer.

- All but one free ride when wealth effects are small, by Joaquim Silvestre.

On Decision-Making (alphabetically, by last name of first author)

- Freedom of choice: John Stuart Mill and the tree of life, by Jorge Alcalde-Unzu, Miguel A. Ballester and Jorge Nieto.

- An axiomatic analysis of ranking sets under simple categorization, by José C. R. Alcantud and Ritxar Arlegi.

- Revealed preference and choice under uncertainty, Walter Bossert and Kotaro Suzumura.

- Nested identification of subjective probabilities, by Jacques H. Dreze.

- Anarchism, postmodernism and realism under confirmatory bias, by Juan Urrutia Elejalde.

On the Economics of Science and Research

- The Evaluation of Citation Distributions, by Javier Ruiz-Castillo.

Open Access This article is distributed under the terms of the Creative Commons Attribution License which permits any use, distribution and reproduction in any medium, provided the original author(s) and source are credited. 